\title{
Skuld, genade en lof in die liturgie ${ }^{1}$
}

\author{
C J A Vos \\ Dekaan: Fakulteit Teologie \\ Universiteit van Pretoria
}

\begin{abstract}
Guilt, mercy and praise in the liturgy

This article argues that guilt, mercy and praise do not always receive the attention they merit in the liturgy. The article aims to enhance the liturgical meaning of the confession of sin and the absolution. The liturgical meaning of these acts is determined by the theological function of the confession of $\sin$ and the absolution. A place in the liturgy is assigned to the Kyrie eleison, the Gloria and the Agnus Dei. This article demonstrates that their proper place is as part of Holy Communion.
\end{abstract}

\section{PROBLEEMSTELLING}

In hierdie artikel word daar gefokus op die liturgiese plek en funksie van skuld, genade en lof in die liturgie. Die hipotese is dat die liturgiese plek en funksies van skuld, genade en lof nie tot sy reg kom nie. 'n Rede in die artikel wat aangevoer word is dat die Kyrie eleison, die Gloria en die Agnus Dei verkeerdelik onder die skuld- en genadeverkondiging ingeskuif en daardeur verdring is.

\section{DIE AKTUALITEIT VAN SKULD}

Die aktualiteit, die werklikheid en die grusaamheid van die skuldvraag is in ons onlangse geskiedenis deur die verslag van die Waarheids- en Versoeningskommissie op ons tafels geplaas (Krog 1998; Meiring 1999; Krog 2003). Ons het opnuut onder die indruk gekom dat ons die skuldvraag nie kan ontsnap of systap nie. Die werklikheid van ons skuld daag ons uit om iets daarmee te doen.

Daar kan vier skuldbegrippe onderskei word, naamlik kriminele, politieke, morele en metafisiese skuld (Schoeman 1999:139-145). Soos alle formuleringe is hierdie onderskeidings egter nie waterdig nie.

\footnotetext{
${ }^{1}$ Hierdie artikel word opgedra aan prof PA Geyser in wie se lewe en werk vryspraak en genade sentraal staan.
} 


\section{Skuld, genade en lof in die liturgie}

- Kriminele skuld. Dit is misdadige handelinge wat objektief vasstelbaar is in dié sin dat dit oortredings van betreklik eenduidige wette is.

- $\quad$ Politieke skuld. Hierdie skuld wys op die optrede van die staat of diegene wat namens die staat handel. Alle burgers is hierby ingesluit, want hulle het hulle bestaan slegs binne 'n bepaalde staatsverband, en hulle moet die gevolge dra van die handelinge van daardie staat aan wie se mag hulle onderworpe is. Elke burger is medeverantwoordelik vir hoe hy/sy regeer word.

- $\quad$ Morele skuld. Vir handeling wat ons as individue verrig, is ons moreel verantwoordelik. Dit geld vir letterlik al ons individuele handelinge, ook vir politieke en militêre handelinge. Nooit kan 'n mens sonder meer sê "'n bevel is 'n bevel" nie. Soos wat misdade misdade bly, ook waar dit in opdrag geskied (en afgesien daarvan of daar versagtende omstandighede was), so is en bly elke handeling ondergeskik aan morele beoordeling. Morele skuld maak ons skuldig voor God en ons naaste.

- $\quad$ Metafisies (of kollektiewe) skuld. Al kan daar tussen individuele en kollektiewe skuld onderskei word, is daar 'n verweefdheid tussen die twee soorte skuld. Daar is 'n solidariteit tussen mense wat elkeen medeverantwoordelik maak vir al die onreg en ongeregtighede in die wêreld, veral vir die wandade wat in jou teenwoordigheid of met jou medewete gepleeg is. Wanneer ons versuim om dit te keer, is ons medeskuldig. Dat ons nog leef, waar ander soveel onreg moes ly of sterf, lê 'n skuldlas op ons. Voor God staan ons skuldig.

In hierdie artikel val die lig op die morele en metafisies skuld. Daar word in hierdie artikel van die hipotese uitgegaan dat die liturgie die aangewese plek is om met skuld af te reken. Op grond waarvan en hoe kom in die artikel aan die orde.

Die mens word ten diepste van sy skuld bewus wanneer hy in 'n ontmoeting tree met die radikaal Andere - die gans Andere (Barth), die Onnoembare (Derrida), die Onbepaalbare en die Oneindige (Levinas), die syn as afgrond en transendensie (Heidegger en Jaspers).

Hierdie ervaring van onmag in die ontmoeting met die radikaal Andere gee, as dit verdring word, aanleiding tot 'n houding van skaamte, deemoed en nederigheid.

Die volgende onthouhandelinge kan onderskei word: tydsonthou, ervaringsonthou en omgewingsonthou. (Vos en Pieterse 1997:230). Die tydsonthou roep die geskiedenis van skuld in herinnering. Deur die tydsonthou word ons bewus van ons individuele en korporatiewe skuld voor 
God en teenoor mekaar. Elke samelewing dra swaar aan sy eie skuld. Hierdie skuld moet voor God, mekaar en diegene wat hieronder gely het, bely word. Ons het niks om op te roem nie, behalwe God se genade. Die belydenis van die legitimering van 'n bepaalde politieke model in Suid-Afrika moet ons oë oopmaak vir die ideologiese blindheid in die verlede en toekoms.

Die ervaringsonthou het die funksie om mense se pynlike ervaringe in herinnering te roep. Deur die liturgiese skuldbelydenis kan ons die leed en die pyn wat ons God, mekaar en ander mense aangedoen het, bely. Hierdie belydenis bring mee dat ons én ander mense se hande en voete gelaaf word.

Die omgewingsonthou bewaar die belydenis van geyktheid en vaagheid. Dit maak die belydenis brandend aktueel en konkreet. Ons verswyg nie ons skuld nie, maar ons lê dit bloot. Hierdie blootlegging beteken dat dit deur vergifnis bedek kan word. Daarom is skuldbelydenis 'n beweging van die nag na die dag, van pyn en verdriet na vreugde.

Uit die besef en erkenning van morele skuld kan vernuwing volg wat ook in die samelewing positiewe vrug kan dra. Insig in morele skuldbesef bring 'n nuwe selfverstaan. Hoogmoed en selfvoldaanheid maak plek vir nederigheid en skroom.

\section{DIE TEOLOGIESE BETEKENIS VAN SKULDBELYDENIS EN -VERGEWING}

Die skuldbelydenis en -vergewing is aan mekaar verwant. Hierdie verwantskap beteken egter nie dat die skuldbelydenis 'n voorwaarde vir skuldvergewing is nie. Die enigste teologiese grond vir sondevergewing is die soenverdienste van Jesus Christus. Op grond van sy soenverdienste oorreed die Heilige Gees mense tot skuldbelydenis en ontvang hulle uit genade alleen skuldvergifnis.

Skuldbelydenis is nie 'n manier om God te oorreed tot vergifnis nie. Dit is die besef van die werklikheid van ons skuld en die grootheid van God se genade (Ps 103; 1 Joh 1). Agter die belydenis staan die werk van die Heilige Gees. Hy wek en oorreed mense tot berou.

Toe die kerk uitgebrei en die gemeentes groter geword het, is die persoonlike skuldbelydenis in die westerse kerk uit die hande van die gemeente geneem en na 'n ampsdraer wat spesiaal daarvoor aangewys is, verwys. Hy was die boetepriester. Die skuldbelydenis verskuif van 'n openbare boete na 'n private belydenis en boeteoplegging, die latere bieg. In die vroeë kerk is die belydenis, al is dit ook teenoor die aangewese ampsdraer uitgespreek, deur openbare boete gevolg. In die eerste eeue het die kerk erns gemaak met sonde. Algaande het die aksent egter verskuif. Die boetedoening is benadruk. 'n Afsonderlike stand is selfs geskep: dié van 
boetelinge. Die herstel van die band met God het tydens die nagmaal plaasgevind (Vos en Pieterse 1997:43). In sy Straatburgse liturgie laat volg Calvyn die vryspraak op die skuldbelydenis. Volgens Calvyn vind dié handeling vóór die preek plaas. Die gemeente gaan om God in die erediens te ontmoet. Daarom lê dit meer voor die hand om die skuldbelydenis en genadeverkondiging in die begin van die diens te laat plaasvind (Jonker s a:170).

\section{DIE LITURGIESE PRAKTYK VAN SKULDBELYDENIS EN GENADEVERKONDIGING}

Daar is verskeie maniere om op die skuldbelydenis te fokus. Dit kan gedoen word deurdat die liturg sekere tekste voorlees (bv Ps 51; 103; Rom 8; 1 Joh 1). Hierna kan 'n paar oomblikke van stilte volg vir meditasie.

Die skuldbelydenis kan ook aan die orde kom deur die lied. Die lied kan op die tekslesing volg, maar dit kan ook afwisselend as 'n selfstandige liturgiese handeling plaasvind. In die liturgie kan die boetelied soms by wyse van beurtsang geskied. Daar is in liedereboeke talle liedere wat as boeteliedere diens kan doen. Veral kan daar van Psalms gebruik gemaak word.

\subsection{Twee liturgiese modelle}

Daar kan in die gereformeerde liturgieë twee modelle ten opsigte van skuldbelydenis en genadeverkondiging onderskei word.

In die eerste model is daar teruggegryp na die Middeleeuse preekdiens, die pronaus. Die pronaus is van die kansel af gehou. Ulrich Zwingli, Marten Micron en Johannes à Lasco het dié rigting uitgebou. Hiervolgens kry die skuldbelydenis 'n plek aan die einde van die diens, ná die preek (Jonker s a:127). Dié beweging het ook in Nederland aanklank gevind (Jonker s a:127; Barnard 1985:547).

Die tweede model sluit aan by die confiteor wat deur Bucer, Calvyn, Pollanus en ander ontwikkel is. Volgens dié liturgiese patroon is die skuldbelydenis se plek aan die begin van die diens geplaas, vóór die preek. Die posisie van die skuldbelydenis het inslag gevind in die Kerkorde van Paltz (1563) en in die vlugtelinggemeente van Frankental. Dit het ook deur Petrus Datheen in Nederland bekend geword (Barnard 1994:257).

By die Konvent van Wesel (1568), wat onder voorsitterskap van Datheen plaasgevind het, moes die gereformeerde kerke kies tussen die Londense liturgie soos voorgestaan deur à Lasco en Micron en die liturgie van Paltz wat deur Datheen verwerk is. Die konvent het ten gunste van Datheen se psalmberyming en kategismus gekies. Die keuse het meegebring dat sy 
liturgiese formuliere uitgegee is. In 1574 het die Sinode van Dordtrecht Datheen se liturgiese geskrifte aanbeveel. Op dié manier het dit kerklike sanksie gekry (Barnard 1994:257-258).

Datheen het wel die openbare skuldbelydenis in die erediens ingesluit, maar die genadeverkondiging weggelaat. Dit was 'n blote vermaning ná die voorlees van die tien gebooie. Dit het aan die begin van die diens voorgekom waar dit die skuldbelydenis wat aan die gebed vir die opening van die Woord verbind is, voorafgegaan het (Barnard 1994:258).

Die verootmoediging en skuldbelydenis het ook sy weg na Nederland gevind. Die Sinode van Middelburg (1581) het egter besluit dat dit nie nodig is nie. Die rede hiervoor was omdat "overmits de bindinghe en ontbindinghe der zonden genoegsaam in de predicatie des Woords geschiede" (Barnard 1994:258).

Hierdie liturgiese ontwikkelinge het meegebring dat die skuldbelydenis en genadeverkondiging nie in die erediens gebruik is nie. Dié liturgiese siening en gebruik het ook in Suid-Afrika neerslag gevind (Jonker s a:126127). In die vyftigerjare is die openbare skuldbelydenis en genadeverkondiging sowel in die Nederlandse Hervormde Kerk as in die Gereformeerde kerke herstel. Hierdie twee liturgiese momente is later ook in die Nederduitse Gereformeerde Kerk in ere herstel (Barnard 1994:258-259).

Aangesien dit in die erediens gaan om die ontmoeting met God, het dit meer sin om die skuldbelydenis en die genadeverkondiging aan die begin van die diens te plaas (Barnard 1994:259).

Die volgende liturgiese oorweging vir skuldbelydenis en genadeverkondiging is die volgende:
Voorganger: Aan almal wat met ' $n$ ware berou en opregte geloof hulle toevlug neem tot hulle enigste Verlosser, Jesus Christus, verkondig ek in die Naam van die Here die vergifnis van sonde. Maar aan elkeen wat in die sonde volhard en die genade verwerp, verkondig ek in die Naam van die Here dat die oordeel van die Here op hom/haar bly solank hy/sy in die sonde bly lewe.

Gemeente: Ek wil die Here loof, met alles wat in my is, wil ek sy heilige Naam loof.

Barmhartig en genadig is die Here, lankmoedig en vol liefde.

Voorganger: Die Here sal ons ons sondes nie bly toereken en nie vir ewig toornig bly nie.

Hy handel met ons 


\author{
nie volgens ons sondes nie, \\ vergeld ons nie vir ons \\ ongeregtighede nie, \\ want so groot as die afstand \\ tussen hemel en aarde is, \\ so groot is sy liefde \\ vir die wat Hom dien. \\ Gemeente: Ek wil die Here loof, \\ met alles wat in my is, \\ wil ek sy Naam loof. \\ Barmhartig en genadig is die Here, \\ lankmoedig en vol liefde. \\ Voorgander: So ver as die ooste van die weste af is, \\ so ver verwyder Hy ons oortredinge \\ van ons af. \\ Soos 'n vader hom ontferm \\ oor sy kinders, \\ so ontferm die Here Hom \\ oor dié wat Hom dien. \\ Gemeente: Ek wil die Here loof, \\ met alles wat in my is, \\ wil ek sy heilige Naam loof. \\ Barmhartig en genadig is die Here, \\ lankmoedig en vol liefde.
}

\title{
5. DIE KYRIE ELEISON, DIE GLORIA EN DIE AGNUS DEI
}

Die vraag wat hier in die brandpunt staan, is dié na die betekenis en funksie van die Kyrie, die Gloria en die Agnus Dei in die liturgie.

Die Reformasie met sy nadruk op die Skrif het die Kyrie en gloria aanvanklik wisselend gebruik en later laat verval (Vrijlandt 1989:187). Tot by die Reformasie was die Kyrie 'n koorstuk. Luther het dit in 'n eenvoudige vorm aan die gemeente oorgedra. In die Straatburgse liturgie (1525) is die Kyrie tot 'n wisselsang tussen die koor en die gemeente omskep. Die gemeente het met die Duitse teks ("Herr, erbarme dich - Christ erbarme dich") op die Griekse teks ("Kyrie eleison - Christe eleison") gereageer (Albrecht 1989:44). Die Kyrie het nie in Calvyn se Straatburgse liturgie van 1538 voorgekom nie. In sy Geneefse liturgie van 1542 het Calvyn die skuldbelydenis van Bucer uit 1537 oorgeneem. 'n Genadeverkondiging ontbreek in die teks. Dit word 'n gebed om vergewing. Die Kyrie en Gloria is opsioneel en verval deurgaans. Dit het te doen met die verset teen die absolusie. Calvyn het dit wel nuttig geag om aan die skuldbelydenis 'n belofte toe te voeg wat die sondaar tot 
hoop op versoening en vergewing opwek. Eers in die sestigerjare van die vorige eeu het die ekumeniese beweging ruimte vir die Kyrie as lied geskep.

Ten einde die teologiese diepgang van die Kyrie eleison te probeer peil, moet die betekenisskakering daarvan eers in die psalms en daarna in die evangelies nagegaan word. Ongeveer twintig keer klink daar in die psalms op: "Here, ontferm U!", of variante daarvan. By Psalm 51:3 ("ontferm U oor my, o God/LXX: eleison me, ho theos!") is die konteks van die uitroep duidelik en konsekwent die van persoonlike skuld (Schuman 2003:191). Hieraan verwant is Ps 41:5, ook vers 11 (LXX: 40:5 en 11). Maar in die gebed duik tegelyk vanaf vers 6 die tipe vyandigheid op, wat in soveel psalms die bidder beweeg tot die uitroep Kyrie, eleison me! (vgl Ps 30:11; $41: 5$ en 11). In die omgewing van die uitroep om ontferming wemel dit van vyande, samesweerders, bedreiging, doodsgevaar en skenders van die goddelike voorskrifte; in een woord: goddeloses (vgl Ps 31:10, 12, 14, 16). In Ps 123 (vgl vers 4 en die aansluitende vervolg in Ps 124) wat deel van die pelgrimspsalms (Pss 120134) vorm, is die "ek" wat om ontferming roep die gemeenskap van Israel self:

Ontferm U oor ons, Here, ontferm $U$ oor ons eleison humas, kyrie, eleison humas!

Vir die eerste, Joods-Christelike getuies van die verhaal van die gekruisigde Jesus as die verhaal van die Lewende, kon die "ek" van bepaalde psalms 'n Messiaanse vulling kry (Schuman 2003:193; Braulik 2003). So word Jesus self die een wat met Ps 30:12 sou kon sê:

Ek was in rou, Maar $\mathrm{U}$ het my van vreugde laat dans, ....

Die vierde Jerusalemse kerk het dit agt dae voor Paasfees gevier volgens die oudste leesrooster wat aan ons bekend is, die Armeense Lectionarium (Barnard 1998:200; Schuman 2003:193). Op soortgelyke wyse kon die evangeliste in die lydensverhaal psalms in Jesus se mond lê waarin die Kyrie opklink. In dié verband kan mens dink aan Jesus se woord oor die verraad van die man wat saam met Hom die tafel deel of aan sy laaste word aan die kruis: "Vader, in u hande gee Ek my gees oor" (vgl Luk 22:21 par. en Ps 41:10, vgl vers 5 en 11; respektiewelik Luk 23:46 en Ps 31:6, vgl vers 10) (Schuman 2003:194). Hierdie Kyrie aanroep van die lydende Jesus is ten diepste ' $n$ roep die goddelike ontferming vir mense in diep nood. 
In twee van die drie lofsange wat Lukas in sy proloog oorlewer, kom die tema van die goddelike ontferming aan die orde (Schuman 2003:188-189). Die twee lofsange is die lofsang van Maria en die lofsang van Sagaria. In Maria se lofsang word in Lukas 1:50 verklaar:

Hy bewys ontferming

van geslag tot geslag

aan dié wat Hom eer.

In die slot van Maria se lied keer die Goddelike eleos/misercordia in Lukas 1:54 en 55 weer terug:

Sy dienaar Israel het Hy te hulp gekom deur te dink aan sy beloftes van ontferming soos Hy dit toegesê het aan ons voorvaders, aan Abraham en sy nageslag tot in ewigheid.

In die lofsang van Sagaria kom die tema twee maal voor. Lukas 1:72 en 73 sluit inhoudelik direk by die lied van Maria aan:

... om Hom te ontferm oor ons voorvaders en sy heilige verbond te onthou. Met 'n eed het Hy dit bevestig aan ons voorvader Abraham dat Hy sou gee dat ons, ...

Die tweede geval kom in Lukas 1:78 en 79 voor: “... danksy die genadige ontferming van ons God. Soos die môreson sal Hy opgaan en uit die hoogte op ons afstraal, om lig te bring aan dié wat in duisternis en in die skaduwee van die dood lewe, om ons voetstappe te rig op die pad van vrede."

Die Kyrie eleison is in die evangelies tot Jesus gerig. In Matteus kom daar vyf voorbeelde hiervan voor (Schuman 2003:190-191). In Matteus 9:27 roep twee blindes wat Jesus volg uit:

Ontferm $U$ tog oor ons, Seun van Dawid!

Net voor die intog in Jerusalem is daar weer twee blindes, nou langs die kant van die pad, wat twee maal roep (Matt 20:30 e v):

Here, Seun van Dawid, ontferm U tog oor ons!.

Hulle volg Jesus ná hulle genesing, met oop oë dus. Tussen hierdie twee genesingsverhale van die blindes, roep eers iemand in belang van haar dogter, en later iemand in belang van sy seun (Matt 15:22 en 17:15): 
Ontferm $U$ oor my, Here, Seun van Dawid! My dogter is in die mag van 'n duiwel, en dit gaan sleg.

Dit gaan in die gevalle om siekte en kwale wat mense buite hulle persoonlike skuld vaskluister aan 'n lot wat hulle nie self begeer of gesoek het nie (Schuman 2003:191). Hulle roep Kyrie eleison! gaan om wat in die liturgie as "die nood van die wêreld" bekend staan.

Hierdie Bybelse kontoere werp 'n lig op die liturgiese funksie van die Kyrie, Gloria en Agnus Dei. In die Kyrie moet daar twee liturgiese funksies bewaar word. In die eerste plek gaan dit om die bewussyn van persoonlike skuld. In die tweede plek gaan dit in die Kyrie om die nood van die mensdom. Dit gaan om die mensdom wat onder die las van skuld sug. In die Romeinse Massaal 1970 word die Kyrie met drie bewuste aanroepinge die meeste gebruik (Schuman 2003:196): "Here, ontferm U, Christus, ontferm U, Here, ontferm U!"

Meestal word daar ná die Kyrie die Gloria as loflied gesing. Die Gloria is 'n baie ou en eerbiedwaardige lofsang, waarmee die kerk, wat in die Heilige Gees vergader, God die Vader en die Lam verheerlik en om ontferming smeek (Heinz 2003:33). Die eie aard van die Gloria kan ook in 'n mosaïek van tekste waarin die die Kyrie weer terugkom, in kombinasie met die Agnus Dei, aangebied word.

'n Liturgiese voorstel wat die Kyrie, die gloria en die Agnus Dei in een teks naatloos weef, is die volgende:

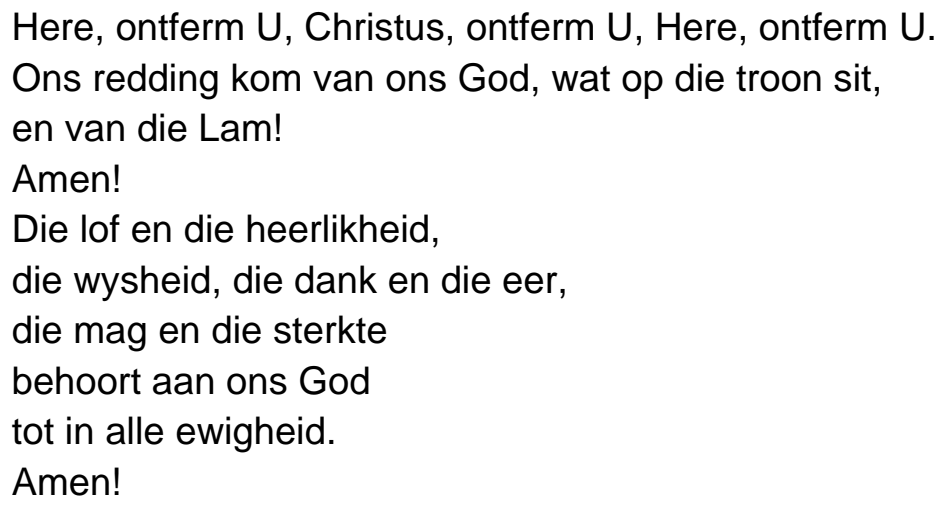

(Op 7:10, 12)

Die Kyrie eleison kan ook gesing word. Lied 248 kan vir dié doel gebruik word. Die Gloria kan ook by wyse van 'n lied uitgedruk word (Jossutis 1991:234). In dié verband kan aan Lied 180, 223 en 367 gedink word.

In die Gerformeerde liturgie het die Kyrie en die Gloria onder die skuldbelydenis en genadeverkondiging ingeskuif ('n voorbeeld hiervan is 
Strydom 1994:299). Die Kyrie en die Gloria is egter onlosmaaklik verweef (Josuttis 1991:234), en wel in die liturgiese gebeure van aanroeping om ontferming wat uitmond in die lof oor die ontferming. Die Kyrie, die Gloria en die Agnus Dei kan tydens die tafeldiens gebruik word.

\section{6. 'N LITURGIE VIR DIE LEWE}

'n Liturgie wat die diepte van die genade van God probeer peil, moet 'n liturgiese plek en funksie vir die skuldbelydenis, die genadeverkondiging, die Kyrie eleison, die Gloria en die Agnus Dei inruim. Binne hierdie ruimtes kan die gemeente die genade van God vier.

\section{Literatuurverwysings}

Albrecht, C 1989. Einführung in die Liturgik. Göttingen: Vandenhoeck \& Ruprecht. Barnard, A C 1985. Die erediens. Pretoria: NG Kerkboekhandel.

Barnard, A C 1994. In die kragveld van die Woord en Gees, 251-254. Voortrekkerhoogte: Benedic.

Barnard, M 1998. De heilige Schrift, in Oskamp, P en Schuman, N A (red), De weg van de liturgie: Tradities, achtergronden, praktijk, 195-209. Zoetermeer: Meinema.

Braulik, G 2003. Psalter und Messiah: Towards a Christological understanding of the Psalms in the Old Testament and church fathers. Unpublished Paper presented at the University of Pretoria, 21st August 2003.

Heinz, A 2003. Overwegingen omtrent de kunst om de kerkelijke liturgie te vieren, in Lamberts, J (red), Ars celebrandi of de kunst van het waardig vieren van de liturgie, 17-41. Leuven: Acco.

Meiring, P 1999. Kroniek van die waarheidskommissie. Vanderbijlpark: Carpe Diem Boeke.

Heitink, G 1993. Praktische Theologie. Kampen: Kok.

Jonker, H s a. Liturgische oriëntasie: Gesprekke over de eredienst. Wageningen: Zomer P Keurings Uitgeversmaatschappij.

Josuttis, M 1991. Der Weg in das Leben: Eine Einführung in den Gottesdienst. München: Chr Kaiser.

Krog, A 1998. Country of my skull. Johannesburg: Random House.

Krog, A 2003. Change of tongues. Johannesburg: Random House.

Schoeman, M 1999. Afrikaners en die skuldvraag. Fragmente: Tydskrif vir Filosowe en Kultuurkritiek 3, 139-145.

Schuman, N A 2003. Een schoot van ontferming: Kyrie eleison en de christologische verlegenheid, in Lanser, A, van Nijen, J, Strak, C, \& Stoppels, S, De kunst van ontfermen: Studies voor Gerben Heitink, 187-201. Kampen: Kok.

Strydom, W M L 1994. "Sing nuwe sange, nuutgebore": Liturgie en Lied. Bloemfontein: NG Kerkboekhandel.

Vos, C J A \& Pieterse, H J C 1997. Hoe lieflik is u woning. Pretoria: RGN Uitgewery. Vrijlandt, M A 1987. Liturgiek. Delft: Meinema. 